\title{
THE SIBBENS OF SCOTLAND
}

by

\author{
R. S. MORTON
}

THERE are many well documented forms of non-venereal treponemal (formerly spirochaetal) diseases resembling syphilis. The most widespread is yaws which occurs in the humid tropical areas of the world. Other forms occasionally still seen today are bejel of the swamp bedouins dwelling along the banks of the Euphrates and Tigris rivers, njoreva in Southern Rhodesia and dichuchwa in Bechuanaland. Until little over a decade ago one such form of non-venereal treponematosis was still prevalent in Bosnia. It was eradicated by a mass treatment campaign undertaken jointly by the Yugoslavian Government and the World Health Organization.

Historical examples of non-venereal treponematosis, all of which died out by the middle of the last century are the button scurvy of Ireland, the radesyge of Norway and the spirocolon of Greece. The sibbens or sivvens of Scotland belongs to this group. All these forms of treponemal infection are, in contrast to syphilis, diseases of social contact and have very rarely any origin in sexual contact. They are inseparably associated with poor and primitive living conditions and all that means in terms of lack of personal hygiene. In these respects sibbens can be shown to be no exception.

It is not proposed to discuss the question of Treponematosis $\mathrm{v}$ Treponematoses, that is, whether all treponemal diseases are but geographical, climatic, social or anthropological variants of a single disease or whether they are each a distinct and separate infection. Suffice it to say that since the middle of the seventeenth century venereal and non-venereal forms of treponemal disease have been fairly clearly differentiated on clinical grounds even when both have occured simultaneously within the boundaries of a single country. Such was the case in Scotland. Venereal syphilis and its origin in sexual contact was well recognized from its beginnings. Its introduction into the country has been detailed (Morton 1961). In the case of sibbens several theories about its introduction have been offered. All have one point in common that is that the disease first became recognized in the mid-seventeenth century. Before long its non-venereal origin was generally agreed. Whilst in syphilis the potency of the seed was somewhat more important than the soil the opposite appears to have held true for sibbens. In other words for a full understanding of the latter an appreciation of the living conditions of the people is essential. The importance of all the factors involved, social, nutritional and hygienic, in the spread and presentation of sibbens and how the improving fortunes of the people, together with other measures led to eradication of the disease forms the subject of this paper.

In the seventeenth century not more than one Scot in five or six lived in surroundings which could by the widest description be called urban. Most of the work was therefore carried on in the country districts rather than in the towns which were in consequence trading rather than manufacturing centres. The towns were small. Glasgow boasted 


\section{The Sibbens of Scotland}

no more than 10,000 inhabitants; Aberdeen had 6,000; Perth 5,000 and Stirling and Dundee 3,000 each. In considering the social conditions therefore priority must be given to the state of arable farming as the principal determinant of the social status of the people. Although there were significant manufacturing advances affecting a minority of those in the burghs of the east coast, for most Scots the supply of their daily bread remained the most insistent daily concern. As the century advanced rival pursuits were only mildly challenged as the main means of livelihood.

What then was the farming potential of the country? Reports of visitors vary greatly and are in some measure conflicting. One writes 'The country lay a mere waste, the pasture and meadowlands gnawed to the quick and strewed with the carcasses of dead sheep'. Sir Thomas Craig on the other hand in his De Unione Regnorum, stated that natural foods were plentiful and that death from famine was less frequent in Scotland than either England or France. Nevertheless there was uncertainty in agricultural production and poor husbandry dictated the record of diet. Traditionally the Lowlands fared better than the Highlands. Even within the Lowland region some areas had a more enviable reputation than others for high productivity. Where drainage was adequate the tendency was to till intensively and to crop the soil to exhaustion and then abandon it to revert to a state of nature.

Thus up to the eighteenth century the country continually laboured under restriction on the grain producing capacity, tolerated a primitive and inefficient field system and employed only outdated implements. The traffic in cattle to the south and to England and the export of half-a-million hides and skins, representing on average of one carcass for human consumption annually, cannot be rated as exceptional. Social and political unrest were rife and instability of land tenure prevailed in all ranks of society. The witticism that when the Devil showed Christ all the countries of the world he kept his thumb over Scotland has a genuine medieval ring of truth.

At the time of Cromwell's defeat of the Scots at Dunbar in 1650 therefore Scotland had long been an impoverished country. It is to the soldiers of Cromwell's army of occupation that most writers attribute the introduction and spread of sibbens. The term 'Cromwell's curse' is mentioned by some. There were 4,500 men in the army of occupation (Croft Dickenson 1961). They were widely scattered throughout both Lowlands and Highlands in detachments varying from 35 to 1,200 at Stirling, the headquarters of the force. Enquiry has not brought to light any records of medical men attached to the army. It seems likely that Cromwell used, for the care of his outlying patrols, local practitioners as and when necessary. At one time he used Heriot's Hospital, now a boys' school, for men requiring in-patient care.

There is no record of sibbens in England but it is a well known that yaws was recognized there. It was very adequately described by Sydenham in 1681. Some might think the two diseases-yaws and sibbens-to be one and the same, the alteration in presentation being affected by climatic and social conditions. Of this there is no proof.

Freer (1767) was the first to acclaim the Cromwellian origin. Hill (1772) believed this theory and also blamed Cromwell's men for introducing the small and the great pox although he conceded that the native population spread all these diseases. An element of confusion exists in differentiating yaws from sibbens. The name originally 


\section{R. S. Morton}

given to sibbens was yaws (Cullen 1911) and this term persisted in the country areas of south-west Scotland for a long time. Hill (1772) believed the reason for this was that yaws was the term used by sailors returning to west coast ports from the West Indies. The possibility that shipwrecked sailors from a Westindiaman may have introduced infections was not overlooked. Gilchrist in a communication to the Philosophical Society of Edinburgh in 1765 (published 1771) used both names but stated that Scottish yaws was not the same as tropical yaws - 'a very different malady'. Gilchrist (1771) also emphasized the unsparing infectivity of the disease and that its appearance in any area struck terror into peoples' hearts. Pattison (1799) commenting on the familial nature of many outbreaks says that it 'frequently spreads rapidly over a village'.

Pennant (1774) an English layman who toured the Highlands extensively reported that the disease had been widely prevalent there fifty years previously and was "brought by the military from Flanders'. He describes it as 'blotches on several parts of the body often turned into a gangrene'. The first medical description of sibbens is generally credited to Freer (1767). There is some doubt from his thesis whether he actually saw cases. Hill (1772) however undoubtedly did and in various parts of the country. He believed that sibbens was 'not peculiar to Scotland'. That it resembled yaws he was in no doubt. He described it thus 'A pocky cock with a scabbed hen producing a yaw chick'. This suggests that, like Freer, Hill believed sibbens to be a mild form of venereal lues. He believed it had been prevalent in outbreaks for many years, was not by any means new and had been described by English authors. He was prepared to agree that it was milder than 'French pox' and made the important point that unlike that disease it was commoner in the country districts than in the towns where syphilis prevailed. While denying the possibility of sexual contact as the origin of sibbens in the individual he concluded that 'syphilis venerea and sibbens are precisely the same disease'. Hill was the first to use the term 'Scotch pox' for sibbens.

The problems of differential diagnosis and nosology seem to have plagued many authors. One is quoted as calling sibbens 'a liminary or middle pox'. Pattison (1799) tried to trace cases to those infected with venereal lues and failed. He was in no doubt however that sibbens was the more infectious of the two conditions, adding that if lues were as contagious the state of large towns 'would be truly dreadful'. Like Freer, who suggested in his thesis a 'free organism' as the cause of sibbens, Pattison believed the disease had its 'own specific poison'. Hibbert (1826) saw yaws and sibbens as identical. In support he emphasized the social background to its spread thus'Sibbens are the engendered product of rank uncleanliness, fed and fostered by unwholesome food and filth'. He noted, as others did that children were frequently infected. Here we have a parallel with other forms of non-venereal treponematosis, in particular yaws where it is generally agreed some 75 per cent of all infections occur before the age of 14 years.

Starting with Freer almost all authors subscribe to the oral contact theory of spread. Freer, underlining the Cromwellian origin, points out that Cromwell's soldiers frequently shared their tobacco pipes with the native population when fraternising with them. Wills (1884) goes further and mentions kissing and shared eating and drinking utensils. Some of these points support the view that sibbens 


\section{The Sibbens of Scotland}

could be a social and climatic variant of yaws. It certainly shows it to be radically different from syphilis in its mode of spread.

Gilchrist (1771) who saw cases in Galloway noted that the disease had a predilection for the mouth, commonly affecting the throat, uvula and tonsil all of which went on to ulcerate severely. Such lesions were frequently associated with thrush. The buccal mucosa and corners of the mouth were often affected. Extensive destruction of tissue even of nasal bones and palate appears to have been common and Gilchrist notes that some babies 'perished for hunger, not being able to suck or swallow'. Mostly these children with sibbens were of the 'lower ranks', 'but some of good condition have lost children by it'. Skin lesions followed. They started as small pustules of a bluish-red hue with a dry crust and a red edge. They tended to spread and coalesce and occasionally to ulcerate. Lesions could be widespread, coming and going 'and leaving great deformity of the skin'. In some cases 'in a short time a fungus or spongy substance sprouts up much like a rasp or strawberry, elevated one half above the surface and when fully formed appears as if set in a socket to receive it'. Such lesions he tells us 'are indolent and tender'. It is this appearance which gives the disease its name. 'Suibbean' is a Gaelic word for raspberry. The English ' $s$ ' terminally, is used to make the plural as in other words of Gaelic origin e.g. claymores, brogues. Pronounced with a slenderly aspirated 'b' as in Spanish, sibbens often appears in writing as 'sivvens' and more rarely as 'civvens' (MacArthur 1953).

Benjamin Bell (1793) who was well acquainted with syphilis in Edinburgh also saw cases of sibbens. Although he believed the disease to be 'one disease with syphilis' he noted that it had no connection with concomitant gonorrhoea or a primary genital sore as did the venereal lues. He subscribed to the belief that spread was by sharing eating and drinking utensils with those already suffering from oral lesions. He found that for the first few weeks there was little complaint apart from sore throat or hoarseness. Once ulceration began however it spread rapidly and not infrequently extensively. Skin lesions, some with ulceration, he saw on all parts of the body - around the anus, on the thighs and legs, abdomen, breasts, arms, fingers, toes, scalp and even the genitals. These lesions varied greatly between individual cases, as observed earlier by Gilchrist, from 'tubercles or hard ulcerated knots' to the more characteristic 'soft, spongy excrescences, in size and colour resembling a common rasp'. Unlike syphilis bone lesions and buboes were rare. Bell considered congenital infection possible. Of more importance was his emphasis on the familial nature of cases particularly the danger to babies from nursing mothers with lesions around the nipples. Csonka (1953) has drawn attention to a similar state of affairs pertaining in bejel, the non-venereal treponematosis of the swamp-dwelling bedouins.

Pattison (1799) who dealt with an outbreak in Dumfries was emphatic about the early nature of oral lesions believing that dermal 'funguous excressercess' generally followed these. There is some resemblance here to the primary and secondary stages of syphilis and the 'mother' yaw 'daughter' yaw sequence in tropical yaws.

Nineteenth-century descriptions show the sibbens as less virulent and the lesions to be altogether milder. Adams (1807), a very astute observer and thorough recorder, visited colleagues in Dumfries. He met Dr. Gilchrist (a son of the one already quoted), 


\section{R. S. Morton}

two other general practitioners, Maxwell and Halliday, and a surgeon named Milligan. With their co-operation he was able to see and examine personally six cases of sibbens. He gives a detailed description of each. Oral lesions prevailed in the early stages. They tended to be less severe than earlier descriptions had led him to expect. Skin lesions he also found to be less exuberant. The raspberry appearance, Adams tells us, was no longer insisted upon by the local practitioners. He catalogues the points of difference between syphilis and sibbens. In the former, ulcers have a 'callous edge and base' whilst in the latter such lesions are clean, phagedenic and with no pus. The skin lesions of syphilis he describes as coppery, elevated and scaly whilst those of sibbens are 'dark brown, thin and crusted with a strong scab'. Bony lesions, common in syphilis, did not occur in sibbens. He confirmed the difference in geographical distribution of the two diseases in Scotland and the poverty of some of the sibbens-ridden patients he considered worthy of comment.

Hibbert (1826) saw cases in the Shetlands. He noted that the skin lesions started with a white or grey 'scurff' and some developed 'shooting up red fungus to become crusted'. Wills (1844) gives us the last clinical report of a group of personally observed cases. He supports the view that lesions are milder than formerly. The natural history of the infection was to reach its height in two or three months. He observed natural cure in some. Thomas (1849) agrees that sibbens grew milder with time and attributes this to better social conditions.

Jonathan Hutchinson $(1896,1897$ and 1900) described sibbens under the colourful title of 'Frambosia Cromwelliana'. The differential diagnostic points he makes may be listed as follows:

Sibbens

1. No primary lesion

2. No buboes

3. Affects children

4. Throat lesions-appear early

5. Frambosian (raspberry) skin lesions

6. Contagious ++

7. Smells ++

8. Bones rarely affected and then nasal

9. One attack usual

\section{Yaws}

Primary lesion

No buboes

Affects children

Throat lesions-later

Frambosian

(raspberry) skin lesions

Mildly contagious

No smell

Long bones commonly affected: nasal and palatal occasionally

One attack usual
Syphilis

Primary lesion

Buboes common

Affects adults

Throat lesions-late

Frambosian skin

lesions rare

Mildly contagious

No smell

Long bones; nasal and palatal only occasionally

Several attacks not unusual

Hutchinson emphasizes the absence of a primary lesion in sibbens. This is surprising. Even this brief clinical review strongly suggests that the oral or throat lesions were in fact the primary lesions of the disease.

The last recorded case of sibbens occured in Banff in 1851 (Cullen 1911).

All writers touching on therapy are agreed that mercury, usually given orally as 


\section{The Sibbens of Scotland}

the sublimate, was the treatment of choice. Smaller doses than in syphilis were generally agreed to be adequate so long as regular treatment was continued for two or three weeks after the disappearance of all lesions. Too early withdrawal of therapy could be followed by clinical relapse. Dosage to the point of salivation, essential in an anti-syphilitic regime, was regarded as unnecessary. Adams (1807) noted that while mercury acted slowly in syphilis, resolution of sibbens lesions was early and prompt. Healed lesions he said left paper-white scars. He agreed that mercury, fumed with a hot iron, could prove adequate. Hill (1772) mentions that Peruvian bark could be prescribed with mercury as an adjuvans. Adams also tried vaccination with cowpox vaccine. With the passage of the vaccine fever lesions of sibbens disappeared but were wont to reappear after six weeks and required mercury for permanent elimination.

Thomas (1849) emphasized the need for 'nourishment' and Wills (1844) drew attention to cleanliness as a requirement in both prevention and cure. Such social awareness had been first stressed by Ebenezer Gilchrist (1771). His contribution must rank amongst the earliest pamphleteering efforts at health education by a physician. The footnote to his paper is worthy of reproduction verbatim: 'As this paper is to be published as a sheet and dispersed among the lower class of people, in this part of the country where information is desired, it is written in plain manner and the terms are explained in words the most familiar to them'.

Gilchrist is the first to see that a high standard of personal hygiene, embracing all sections of society is essential to prevention. He commends the use of individual eating and drinking utensils. He cautions against the employment of itinerant servants not providing themselves with these articles. Wet nurses he insists must be medically examined frequently. His lead is clear, concise and authoritative. Hibbert (1826) alone could add to it, and then but little. The popularity of Prestonpans for seabathing in the early nineteenth century is attributed to him.

There seems little doubt that in sibbens we are dealing with a form of treponematosis and one which more closely resembles the non-venereal forms than the venereal. Like these, and more especially like yaws to which it bears a close resemblance, its contagiousness was marked. The degree of infectivity was to some extent determined by the social state and personal habits of the people. The apparent virulence in the earlier years we can ascribe without reserve to the poor nutritional state of many of the afflicted and the predisposition this gave not only for a paucity of humoral reaction but more especially to secondary infection. The steady relief of poverty by improving techniques on the land diminished nutritional deprivation. Growing availability of amenities brought something akin to civilized living to country dwellers. These general factors in concert with a conscious awareness of the need for prevention, its practice and the steady curtailment of the reservoir of infectious cases by early and effective treatment conspired together to successfully and permanently eradicate the sibbens of Scotland.

\section{REFERENCES}

Adams, Joseph, Observations on Morbid Poisons, 2nd ed., London, J. Callow, 1807. Beul, Benuamn, Treatise on Lues Venerea, Edinburgh, James Watson, 1793. 


\section{R. S. Morton}

Croft, Dickenson A., A Source Book of Scottish History, 1961, 3, 465.

CsonkA, G. W., Brit. J. vener. Dis., 1935, 29, 95.

CulleN, G. M., 'Concerning sibbens and the Scottish yaws', Caledonian med. J., 1911, 8, 336.

FreER, ADAM, Dissert. Med. Inaug. de syphilide venerea. Mecron de morbo sibbens dicto, Edinburgh, 1767.

GILCHRIST, Ebenezer, Essays and Observations. Physical and Literary. (Read before the Philosophical Society of Edinburgh, 1765), 1771, 3, 154.

HibBert, S., Edin. J. med. Sci., 1826, 1, 287.

HiLL, JAMEs, Cases in Surgery-to which is added an account of sibbens, Edinburgh, John Balfour, 1772, pp. 223-63.

Hutchinson, J. H., Arch. Surg., 1896, 17, 23.

Idem., Edin. Med. J., 1897, 43, 9.

Idem., Brit. med. J., 1900, $2,561$.

MACARTHuR, W. P., Trans. R. Soc. Trop. Med. Hyg., 1953. 47, 437.

MORTON, R. S., Brit. J. vener. Dis., 1962, 38, 175.

Patrison, in Contributions to Physical and Medical Knowledge, collected by T. Beddoes, 1799, pp. 403-9.

Pennant, Thomas, A Tour in Scotland, 3rd. ed., 1774, p. 59.

SyDENHAM, Thomas, The works of Sydenham .. . by John Swan, third edition, 1763.

Thomas, J., Edin. med. surg. J., 1849, 15.

WinL, Lond. Edin. mthly J. med. Sci., 1844, 4, 282. 